\title{
APTITUD DEL PROFESIONAL DE CIENCIAS ECONÓMICAS DE LA UNIVERSIDAD NACIONAL DEL NORDESTE PARA RESPONDER A LAS NECESIDADES SOCIALES
}

TERESITA M. GONZÁLEZ AZCÓAGA

FACULTAD DE CIENCIAS ECONÓMICAS - UNNE

PRIMER PREMIO. Categoria: Estudiantes

"Precisamente porque somos humanos, somos "responsables" de crear las condiciones que optimicen la humanización de la vida”. Denis Goulet 


\section{GENERALIDADES SOBRE EL VOLUNTARIADO COMO ORGANIZACIÓN}

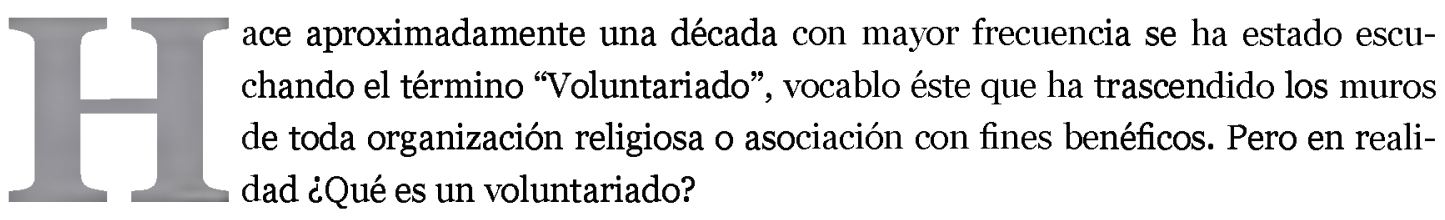

Remitiéndonos a algún diccionario, el voluntariado es definido como "el trabajo de personas que sirven a una comunidad o al medio ambiente por decisión propia y libre".

La palabra voluntariado con su actual significado no se desarrolla hasta el siglo XX, siendo utilizada hasta ese momento para describir a la "gente ligada a actividades religiosas" (Karl)1.

Posteriormente han surgido conceptos dables de destacar que confluyen en conceptualizar al voluntariado como una organización captadora de personas con ansias de prestar servicios, sostenidas por su espíritu solidario, pero con una característica no menos importante, el hecho de que esa actividad fuera realizada en momentos de ocio.

Hasta aquí se pueden observar enunciaciones que caracterizan a este fenómeno como un hecho social, proveniente de la buena voluntad del ser humano, que una vez que ha cumplido con sus responsabilidades laborales o sus deberes de estado, se pone a disposición desinteresada de una comunidad o grupo social.

Según el Comité de Expertos sobre Voluntariado ${ }^{2}$ existen tres elementos que pueden definirlo:

- Una actividad no onerosa, si bien se puede permitir el reembolso de gastos o algún pago simbólico.

- Una actividad que beneficie a un grupo social o persona distinta de quien la realiza.

- Una actividad libre, dependiente de la voluntad de quien la lleva a cabo.

Respecto de este último elemento se puede discutir, ya que dependiendo del accionar político o estructura jurídica de cada país, pueden existir motivaciones para personas que cumpliendo determinadas condiciones, por ejemplo de edad o nivel de estudios, se encuentren atraídas en participar de un trabajo voluntario a cambio de una asistencia explicita, como ser alimentos.

\subsection{Diferentes enfoques y concepciones del voluntariado}

El voluntariado puede ser abordado desde diferentes enfoques resaltando cada uno un aspecto diferente que nos ayuda a ver las distintas vertientes que puede tener este fenómeno:

- Humanista: Es una forma de demostrar la voluntad humana de cuidar a los demás.

- Radical: El voluntariado trata de cambiar las estructuras que no funcionan.

- Necesidad Económica: Ayuda a que el estado pueda facilitar la prestación de servicios con menos recursos.

- Entrada al mercado laboral: Es una manera de adquirir experiencia que aumenta el número de empleados y ayuda a encontrar trabajo remunerado.

\footnotetext{
${ }^{1}$ Karl, Barry “The por volunter: Anessay on relation between history and myth" en Social Service Review, 1984, vol 58.

${ }^{2}$ Reunión del grupo de trabajo de expertos sobre voluntariado y desarrollo social. Nueva York, 29 - 30 de noviembre de 1999.
} 
- Sociedad Civil: Los voluntarios contribuyen a reforzar el tejido social de su comunidad, promoviendo la libertad y la democracia.

\subsection{Tipos de Voluntariados}

Podemos clasificar a los voluntariados de acuerdo a criterios como:

Según el Área de acción: Esta clasificación tiene en cuenta el ámbito de acción

- Voluntariado en acción social: es aquel en el se colabora en un proyecto del país donde se reside y en campos como la discapacidad o la migración.

- Voluntariado ambiental: es el que se encuentra relacionado con proyectos de defensa y protección del medio ambiente.

- Voluntariado en emergencias: es el que se encuentra relacionado con crisis o catástrofes naturales.

- Voluntariado en cooperación: cuando se desarrollan en una comunidad perteneciente a un país distinto de donde se reside.

- Voluntariado cultural: es aquel en el que se colabora en la organización de actividades relacionadas con la cultura como ser museos, bibliotecas, salas de arte.

Según la forma de entender la finalidad del voluntariado

- Voluntariado asistencialista: es el que alivia las consecuencias de una exclusión, sin buscar formas de cambiar esa situación.

- Voluntariado desarrollista: es aquel que busca un cambio en la exclusión, dotando a las personas que la sufren de herramientas para superarla.

- Voluntariado activista: busca un cambio en la exclusión, denunciando las condiciones que la producen y exigiendo que éstas desaparezcan.

- Voluntariado como mano de obra barata: muchas organizaciones lo utilizan para reducir costes.

Según se encuentre involucrada una organización

- Voluntariado formal: cuando el voluntariado se realiza dentro de una entidad constituida.

- Voluntariado informal: cuando se realiza sin asociación o fundación que lo ampare.

Según el tiempo dedicado al proyecto

- Voluntariado puntual o microvoluntariado: se requiere una participación reducida a unas horas o días.

- Voluntariado en vacaciones: la persona se involucra durante el tiempo de sus vacaciones, aunque muchas organizaciones ofrecen y exigen recibir una formación anterior y participar en un periodo de reflexión y activismo posterior. 
- Voluntariado continuado: cuando se requiere un compromiso habitual de la persona voluntaria.

Según la actividad realizada

- Voluntariado pedagógico: la persona voluntaria se implica en un proyecto de enseñanza.

- Cibervoluntariado: la persona voluntaria participa en un proyecto de enseñanza del uso de la tecnología.

- Voluntariado intelectual: la persona voluntaria asesora a una organización o a varias personas sobre posibles mejoras de un proyecto.

- Voluntariado para la acogida temporal: cuando un voluntario acoge en su propia casa a una persona.

- Voluntariado en apoyo emocional: el voluntario colabora apoyando a personas que sufren una situación personal muy difícil.

\section{ASPECTOS RELEVANTES DE LOS VOLUNTARIADOS}

\subsection{Motivaciones que dan origen}

Sin dudas un voluntariado trasciende los límites del empleo remunerado y de las responsabilidades normales. Quienes lo integran se encuentran convencidos de que la actividad a realizar es útil para la humanidad y uno mismo. Es en estos términos donde se puede profundizar el significado del espíritu humanitario y compasivo de las personas.

La palabra "voluntario", aplicada a una persona, no significa necesariamente que trabaja sin remuneración, sino que trabaja por propia voluntad, sin imposición exterior. En un voluntariado abunda el espíritu de servicio, servir significa dar, sacrificar una parte de sí mismo de lo que posee, a favor de otros.

Las motivaciones que dan origen a un voluntariado están estrechamente vinculadas a la necesidad de dar, no lo que abunda en uno, sino lo que el otro necesita. Está comprobado, por diferentes modelos sociológicos como las escalas de necesidades, que el ser humano una vez que ha satisfecho sus necesidades básicas o fisiológicas, busca satisfacer otras como la de seguridad, reconocimiento o autorrealización, ahora bien, para muchas personas, el hecho de pertenecer a un voluntariado con el fin de prestar servicios a sus semejantes, se torna en una necesidad cuasi fisiológica sin embargo para otros esta condición aparece en momentos en que se busca saldar alguna necesidad de carácter meramente social.

En cualquiera de estas circunstancias, se puede afirmar que la principal motivación que da origen a los voluntariados es una necesidad manifiesta por ayudar, sostenida por dos pilares: el espíritu humanitario y la voluntad de realizarlo. 


\subsection{El Voluntario: la persona}

El hecho de ser voluntario es una decisión que se toma de forma reflexiva y responsable ante una determinada situación, también podemos planteamos actuar como voluntarios como forma de resolver un determinado problema en el marco de una organización. No es una acción impulsiva que aparece ante determinados sucesos y desaparece cuando culmina el impulso que le dio origen. Es un compromiso que se toma por iniciativa propia, es por esto que no se consideran voluntarios personas que realizan una acción sujeta a obligaciones legales.

El voluntariado además se ejerce de forma desinteresada, no pueden considerarse voluntarios las personas que reciben un salario o gratificación, pero ello no implica que puedan reintegrarle todos los gastos que ocasione el ejercicio de su acción voluntaria.

Un voluntario es una persona simple con tantas o más necesidades que la persona a quien se quiere ayudar. El voluntario no es un ser sobrenatural, muy por el contrario, en la mayoría de los casos se trata de personas que han pasado por situaciones difíciles de soportar o bien se han puesto en el lugar del que necesita. Es alguien que opta por transitar la vida sin perder la oportunidad de minimizar las amenazas que aquejan a los demás.

Si buscamos aspectos propios característicos del ser humano-voluntario, difícilmente podamos encontrar, ya que éstos pueden estar influenciados por las realidad socioeconómica del lugar. Pero se pueden nombrar algunos valores comunes a todo voluntario, estos valores son universales y como tal trascienden toda frontera ideológica, social o geográfica, ellos son:

- Altruismo: porque se pretende conseguir el beneficio de otros sin recibir ninguna gratificación económica por ello.

- Responsabilidad: como obligación, ya sea moral, personal o legal. Tiene un efecto directo en otro concepto muy importante como es la confianza.

Decencia: Constituye aquel valor que nos hace conscientes de la propia dignidad humana, a través de él los sentidos, la imaginación y hasta el propio cuerpo son resguardados.

- Respeto a los semejantes: el hecho de desarrollar tareas en un voluntariado permite que cada actividad se lleve a cabo pensando en el otro, y desde entonces se inicia el respeto por la necesidad, limitaciones o gustos de la otra persona.

- Lealtad: implica cumplir con lo prometido, corresponder con quien tiene una necesidad.

- Superación: Es una acción que requiere inmediatez, planeación, esfuerzo y trabajo permanente.

Es importante recordar que al voluntario no le basta conocer los valores, sino además necesita darlos a conocer y reforzarlos para lograr un cambio de actitud, un cambio de realidad. 


\section{LA RESPONSABILIDAD SOCIAL EMPRESARIA: ¿OPCION U OBLIGACIÓN DEL PROFESIONAL DE CIENCIAS ECONÓMICAS?}

Álvarez ${ }^{3}$ afirma: “La consideración de la responsabilidad social de la organización no excluye la responsabilidad social del dirigente”. Debemos considerar que la organización es un sujeto independiente de la figura del administrador o profesional de Ciencias Económicas, una organización está sujeta a la responsabilidad social en cuanto tiene que cumplir con múltiples objetivos, entre ellos los sociales. El profesional a cargo está sujeto a la ética, y ésta y la responsabilidad social de la empresa están estrechamente vinculadas. La empresa actual tiene una responsabilidad por su comportamiento en el mundo económico, por el cumplimiento de las leyes y por el respeto de la persona. Hoy las empresas no solo se limitan a producir bienes y servicios que permitan obtener resultados económicos positivos, sino además se ha incorporado la posibilidad de cumplir con objetivos sociales. Esto no significa que la organización sea una entidad encargada de arreglar los problemas sociales, solo trata de dar respuesta a las demandas de la sociedad.

Esta incorporación del aspecto social incide en la planificación, las decisiones y el accionar de toda la organización, y es a través de ellos que se observa una evolución de la responsabilidad social, ya que en un primer momento se creía que si la maximización del beneficio y los objetivos económicos eran buenos para la organización lo eran también para la sociedad. Posteriormente aparece la necesidad de equilibrar los valores sociales con los económicos y finalmente se considera que lo que es bueno para la sociedad lo es también para las organizaciones.

A partir de esta evolución en el comportamiento de las organizaciones, surge también un cambio en el rol del profesional de las ciencias económicas, ya que en su accionar queda expuesta la presencia de valores inherentes o no a cada persona.

Al fijar los objetivos de una organización y formular las políticas con un tinte social se deben precisar los valores sobre los que se funda dicha organización; establecer los criterios para orientar las decisiones administrativas y de operación en lo social; anticipar los procesos y las consecuencias de esas decisiones; diseñar reglas de juego y mecanismos para la revisión y la evaluación de esos criterios, decisiones y consecuencias. Todo esto es realizado por el mismo profesional en ciencias económicas o bien el entorno bajo su supervisión.

En síntesis, la consecuencia fundamental de este enfoque es que la eficiencia y funcionamiento con arreglo a normas éticas que respondan al bien común, comprende a toda la sociedad y no se limita al ámbito exclusivo de cada organización en particular. La responsabilidad social no significa que las organizaciones deban realizar funciones antieconómicas, la eficiencia y eficacia económica es anterior a la social.

Una manifestación de esa responsabilidad social es el accionar de los voluntariados, ya que actualmente, la mayoría de ellos, se estructura como organizaciones sin fines lucrativos cuyo objetivo primordial es atender una necesidad social.

${ }^{3}$ Álvarez, Héctor F. "Administración un enfoque interdisciplinario y competitivo" (1985) 
El profesional de las ciencias económicas puede obtener como objetivo el lucro, esto no quiere decir que sea el principal o el único objetivo, ya que en última instancia el objetivo es la rentabilidad, y esta es la base para lograr sus objetivos sociales.

La responsabilidad social incide en el desarrollo de las organizaciones porque existen interrelaciones entre las necesidades de la sociedad y los objetivos de los profesionales. De esta forma se puede afirmar que la responsabilidad social puede ser considerada como una opción que se le presenta al profesional de las ciencias económicas, pero esta opción puede convertirse en una obligación si se piensa como ventaja competitiva al momento de evaluar el contexto dinámico en el que se opera.

\section{EL ESTUDIANTE DE CIENCIAS ECONÓMICAS DE LA UNIVERSIDAD NACIONAL DEL NORDESTE Y SU ACCIONAR EN EL VOLUNTARIADO}

En numerosas oportunidades, a quienes somos estudiantes de ciencias económicas se nos ha señalado como personas cuyas únicas aspiraciones personales y laborales se centran en la obtención de rentabilidad. El hecho de analizar constantemente situaciones que impliquen hipotéticas tomas de decisiones, hace que se nos incluya dentro de un ámbito donde el carácter humanitario tiene poca o nula trascendencia.

El hecho de que el estudiante de ciencias económicas, durante su preparación como profesional se vaya nutriendo sobre aspectos relativos a gestión organizacional, procedimientos y técnicas administrativas, tratamiento tributario y legal, análisis de contextos macro y microeconómicos, no significa que se encuentre ajeno a aquellos problemas sociales pocos relacionados con la vida empresaria.

El perfil del egresado de cada una de las carreras difiere respecto de su esencia; así se podrá observar que el aspecto de la responsabilidad social tiene mayor relevancia en algunas.

Para la realización de este trabajo se llevo a cabo una encuesta a veinte estudiantes elegidos de manera aleatoria, con el objeto de investigar el alcance que tiene la responsabilidad social y el voluntariado como una forma de expresión de la primera.

La encuesta fue realizada a través de un cuestionario sencillo, donde cada persona tuvo la posibilidad de expresarse de manera libre e individual.

A continuación se muestran tablas que resumen los resultados de esta investigación. 


\begin{tabular}{|c|c|c|c|c|c|c|c|c|c|c|}
\hline & 21 & (Chaco) & Contador & 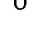 & & & Civiles & 80 & y enfermos & relación \\
\hline Hombre & 21 & Puerto Tirol & Contador & 11 & Poca & Mucha & $\begin{array}{l}\text { Empresas y } \\
\text { estudiantes }\end{array}$ & No & $\begin{array}{l}\text { Asistencia a } \\
\text { empresas }\end{array}$ & $\begin{array}{l}\text { Poca } \\
\text { relación }\end{array}$ \\
\hline Hombre & 19 & Resitencia & Contador & 13 & Poca & Mucha & $\begin{array}{l}\text { Empresas, } \\
\text { estudiantes y } \\
\text { Asoc. civiles }\end{array}$ & No & $\begin{array}{c}\text { Asistencia a } \\
\text { menores en } \\
\text { situación de riesgo }\end{array}$ & $\begin{array}{l}\text { Poca } \\
\text { relación }\end{array}$ \\
\hline Hombre & 22 & Castelli & Contador & 10 & Poca & Mucha & $\begin{array}{c}\text { Empresas, } \\
\text { estudiantes, } \\
\text { Asoc. religiosas, } \\
\text { Asoc. civiles }\end{array}$ & No & $\begin{array}{c}\text { Asistencia a } \\
\text { menores en } \\
\text { situación de riesgo, } \\
\text { asist. a enfermos }\end{array}$ & $\begin{array}{l}\text { Mucha } \\
\text { relación }\end{array}$ \\
\hline Mujer & 21 & Santa Fe & $\begin{array}{l}\text { Lic. en } \\
\text { Adm. }\end{array}$ & 12 & Poca & Poca & $\begin{array}{c}\text { Empresas, } \\
\text { estudiantes, } \\
\text { Asoc. religiosas, } \\
\text { Asoc. civiles }\end{array}$ & $\mathrm{Si}$ & $\begin{array}{c}\text { Asistencia a } \\
\text { menores en } \\
\text { situación de riesgo, } \\
\text { asist. a enfermos }\end{array}$ & $\begin{array}{l}\text { Mucha } \\
\text { relación }\end{array}$ \\
\hline Mujer & 39 & Bs As & Contador & 25 & Mucha & Mucha & $\begin{array}{l}\text { Empresas, } \\
\text { estudiantes, } \\
\text { Asoc. religiosas, } \\
\text { Asoc. civiles }\end{array}$ & $\mathrm{Si}$ & $\begin{array}{c}\text { Asistencia a } \\
\text { menores en } \\
\text { situación de riesgo, } \\
\text { asist. a enfermos }\end{array}$ & $\begin{array}{l}\text { Poca } \\
\text { relación }\end{array}$ \\
\hline Hombre & 22 & Formosa & $\begin{array}{c}\text { Lic en } \\
\text { Economia }\end{array}$ & 10 & Mucha & Mucha & $\begin{array}{l}\text { Empresas, } \\
\text { estudiantes, } \\
\text { Asoc. religiosas, } \\
\text { Asoc. civiles }\end{array}$ & No & $\begin{array}{c}\text { Asistencia a } \\
\text { menores en } \\
\text { situación de riesgo, } \\
\text { asist. a enfermos }\end{array}$ & $\begin{array}{l}\text { Mucha } \\
\text { relación }\end{array}$ \\
\hline Hombre & 21 & Corrientes & $\begin{array}{l}\text { Lic en } \\
\text { Adm }\end{array}$ & 15 & Poca & Mucha & $\begin{array}{c}\text { Empresas, } \\
\text { estudiantes, } \\
\text { Asoc. religiosas, } \\
\text { Asoc. civiles }\end{array}$ & $\mathrm{Si}$ & $\begin{array}{l}\text { Asistencia a } \\
\text { enfermos }\end{array}$ & $\begin{array}{l}\text { Poca } \\
\text { relación }\end{array}$ \\
\hline
\end{tabular}

\begin{tabular}{|c|c|c|c|c|c|c|c|c|c|c|}
\hline Mujer & 27 & S. Peña & $\begin{array}{l}\text { Lic en } \\
\text { Adm }\end{array}$ & 21 & Ninguna & Mucha & $\begin{array}{c}\text { Empresas, } \\
\text { estudiantes, } \\
\text { Asoc. religiosas, } \\
\text { Asoc. civiles }\end{array}$ & No & $\begin{array}{c}\text { Asistencia a } \\
\text { menores en } \\
\text { situación de riesgo, } \\
\text { asist. a enfermos }\end{array}$ & $\begin{array}{l}\text { Poca } \\
\text { relación }\end{array}$ \\
\hline Mujer & 54 & Corrientes & Contador & 26 & Mucha & Mucha & $\begin{array}{c}\text { Empresas, } \\
\text { estudiantes, } \\
\text { Asoc. religiosas, } \\
\text { Asoc. civiles }\end{array}$ & No & $\begin{array}{c}\text { Asistencia a } \\
\text { menores en } \\
\text { situación de riesgo, } \\
\text { asist. a enfermos }\end{array}$ & $\begin{array}{l}\text { Mucha } \\
\text { relación }\end{array}$ \\
\hline Mujer & 26 & Resistencia & Contador & 10 & Poca & Mucha & Empresas & No & Ninguna & $\begin{array}{l}\text { Poca } \\
\text { relación }\end{array}$ \\
\hline Mujer & 29 & Resitencia & Contador & 18 & Poca & Mucha & $\begin{array}{l}\text { Empresas, } \\
\text { estudiantes, } \\
\text { Asoc. religiosas, } \\
\text { Asoc. civiles }\end{array}$ & No & $\begin{array}{c}\text { Asistencia a } \\
\text { menores en } \\
\text { situación de riesgo, } \\
\text { asist. a enfermos }\end{array}$ & $\begin{array}{l}\text { Poca } \\
\text { relación }\end{array}$ \\
\hline Mujer & 32 & Resitencia & Contador & 18 & Ninguna & Poca & $\begin{array}{c}\text { Empresas, } \\
\text { estudiantes, } \\
\text { Asoc. religiosas, } \\
\text { Asoc. civiles }\end{array}$ & No & Ninguna & $\begin{array}{l}\text { Ninguna } \\
\text { relación }\end{array}$ \\
\hline Hombre & 23 & Corrientes & Contador & 8 & Mucha & Mucha & $\begin{array}{l}\text { Empresas, } \\
\text { estudiantes, } \\
\text { Asoc. religiosas, } \\
\text { Asoc. civiles }\end{array}$ & Si & $\begin{array}{l}\text { Asistencia a } \\
\text { menores en } \\
\text { situación de riesgo, } \\
\text { asist. a enfermos }\end{array}$ & $\begin{array}{l}\text { Ninguna } \\
\text { relación }\end{array}$ \\
\hline Mujer & 23 & Corrientes & Contador & 12 & Poca & Poca & $\begin{array}{c}\text { Asociaciones } \\
\text { civiles }\end{array}$ & No & Ninguna & $\begin{array}{l}\text { Poca } \\
\text { relación }\end{array}$ \\
\hline Mujer & 22 & Corrientes & Contador & 7 & Poca & Mucha & Empresas & No & Desconoce & Desconoce \\
\hline Hombre & 28 & Corrientes & Contador & 15 & Poca & Mucha & $\begin{array}{l}\text { Empresas, } \\
\text { estudiantes, } \\
\text { Asoc. religiosas, } \\
\text { Asoc. civiles }\end{array}$ & $\mathrm{Si}$ & $\begin{array}{c}\text { Asistencia a } \\
\text { menores en } \\
\text { situación de riesgo, } \\
\text { asist. a enfermos }\end{array}$ & Ninguna \\
\hline & & & & & & & Empresas, & & & \\
\hline
\end{tabular}


Después de haber analizado las respuestas de los veinte estudiantes encuestados se pueden concluir en tres aspectos sobresalientes:

1. Los encuestados, estudiantes de Ciencias Económicas de la Universidad Nacional del Nordeste alguna vez han tratado el tema "Responsabilidad Social", razón por la cual poseen poca noción sobre el mismo.

2. Los estudiantes encuestados, si bien admiten escaso conocimiento respecto del tema, otorgan mucha importancia al mismo.

3. Los encuestados encuentran poca relación entre su perfil de egresados y las actividades realizadas en un voluntariado.

Los datos anteriores pueden ser analizados con mayor detalle, teniendo en consideración aspectos tales como el número de materias aprobadas, que explicarían tales respuestas.

De igual modo, si se pensara en realizar una investigación cuali cuantitativa en profundidad, debería tomarse una muestra mayor en concordancia con otros parámetros como número de egresados o número de ingresantes por año.

\section{Nociones sobre Responsabilidad Social}

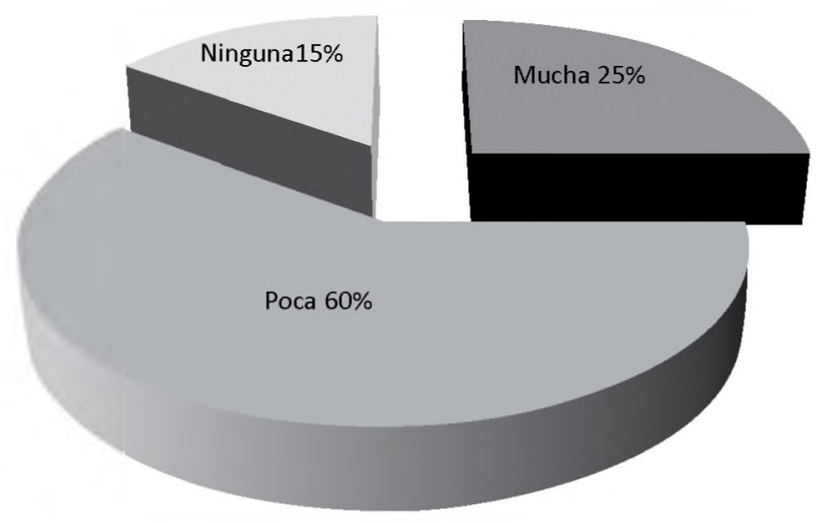

Importancia otorgada a la Responsabilidad Social

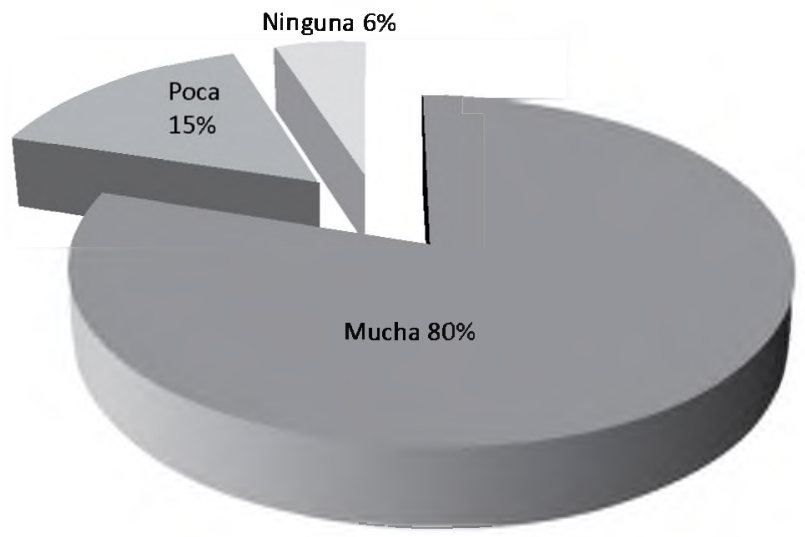


Relaciones entre el perfil del egresado y las actividades realizadas en un voluntariado

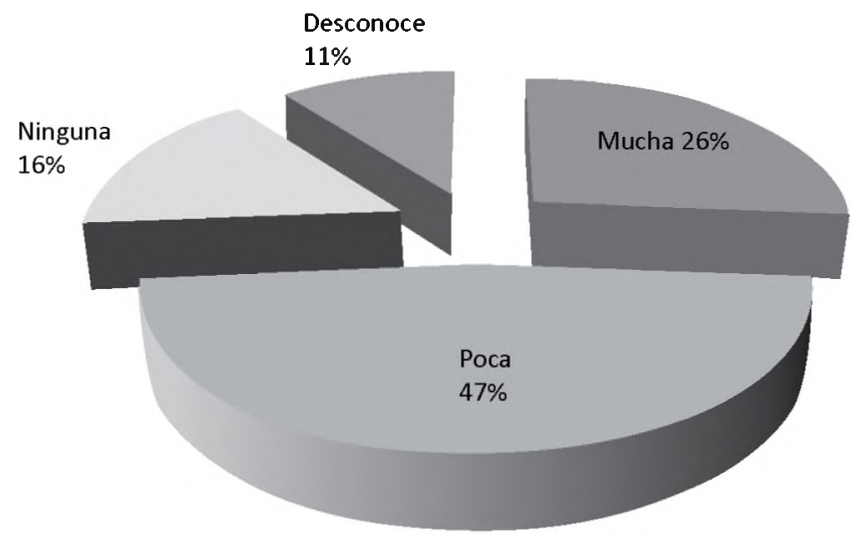

\section{REFERENCLAS BIBLIOGRÁFICAS}

Álvarez, H. (1985) Administración un enfoque interdisciplinario y competitivo. Ediciones Eudecor: Buenos Aires Argentina.

García - Rincón de Castro, C. (2003) Cuaderno de viaje para acompañar experiencias de voluntariado social. Homo Prosocius: Madrid España.

\section{CURRÍCULUM VITAE}

\section{TERESITA MARÍA DE LOS ÁNGELES GONZÁLEZ AZCÓAGA}

Cursa el 5 to año de la carrera Licenciatura en Administración de la Facultad de Ciencias Económicas, Universidad Nacional del Nordeste.

Es técnico Superior en Administración de Empresas, egresada del Instituto Superior "Ntra. Sra. de la Misericordia" Corrientes.

Cursa la Carrera Hotelería y Turismo de la Universidad de Belgrano.

Se desempeña como profesora titular de 21 horas cátedras pertenecientes a la especialidad “Administración de Empresas" en la Escuela Técnica "Fray Luis Beltrán" de la Ciudad de Corrientes Capital.

temagaz@hotmail.com

temagaz@yahoo.com.ar 